\title{
A new case of low modality: Goal PPs*
}

\author{
Fabienne Martin \\ Humboldt-Universität zu Berlin \\ Christopher Piñón \\ Université de Lille
}

\author{
Margaret Grant \\ Simon Fraser University \\ Florian Schäfer \\ Humboldt-Universität zu Berlin
}

\begin{abstract}
This paper provides experimental evidence from German and English against the view that a goal $t o / z u$-PP in combination with a motion verb designates a goal that is reached. We propose that $t o / z u$ have a modal meaning, responsible for the defeasibility of the inference that the goal is reached. We argue that the type of subjects (intentional agent vs. accidental agent or theme) determines the flavor of the (necessity) modal encoded by the preposition (teleological or circumstantial), which allows us to account for the observed variation in the strength of the inference with the type of subjects and the type of verbs.
\end{abstract}

Keywords: path semantics, aspect, manner-of-motion verb, deictic verb of motion, goal PP, intentional vs. accidental agent, low modality, modal preposition, experimental semantics

\section{Introduction}

This paper is devoted to the interpretation of German and English sentences with motion verbs combined with a directional PP expressing a goal, more specifically, to/zu-PPs:

(1) a. Ziggy ist zur Bibliothek gelaufen.

(manner-of-motion verb)

b. Ziggy walked to the library.

c. Ziggy ist zur Bibliothek gekommen.

(deictic verb of motion)

d. Ziggy came to the library.

e. ? $\rightarrow$ Ziggy reached the library.

We address two related empirical questions: How are these sentences interpreted in German and English? Do they entail that the subject's referent reached their goal?

* We are grateful to Artemis Alexiadou, Bridget Copley, Berit Gehrke, Jens Höpperdietzel, Itamar Kastner, Benjamin Lowell-Sluckin, Orin Percus, Fabio del Prete, Giorgos Spathas and Jad Wehbe for valuable feedback. We also thank our SALT 30 reviewers, the RUESHeL group, the audience of OASIS2, the Event Semantics Workshop at HU Berlin and SALT 30. This work is financially supported by DFG award AL 554/8-1 to A. Alexiadou. F. Martin is the corresponding author. 
A new case of low modality: Goal PPs

We look at manner-of-motion verbs (e.g., rennen/run, laufen/walk, etc.) and deictic verbs of motion (come/kommen, as well as go in English). The traditional view is that the inference that the goal is reached amounts to an entailment when a motion verb is combined with to-PPs in a non-progressive sentence, as seen in (e.g.) Piñón 1993 and Smith 1997. The same view holds as well for German sentences with a $z u$-PP, as seen in Haselbach 2017.

(2) Mary walked to [the] school, \#but she didn't actually get there.

(Smith 1997: 64)

We call the traditional view into question and present experimental data suggesting that with $t o / z u$, the inference is cancelable in both languages in an appropriate context with manner-of-motion (walk/laufen) verbs as well as with go in English, but is nevertheless stronger with come-verbs in both languages. In a nutshell, our proposal is that to and its German counterpart $z u$ have a modal meaning, and thus illustrate a new case of "low modality", that is, modality in structures dominated by VP or NP (Arregui, Rivero \& Salanova 2017). The paper is structured as follows. Section 2 summarizes Zwarts 2005 on to-PPs. Section 3 presents problems for the traditional view on $t o / z u$-PPs. Section 4 is devoted to the experiments and Section 5 presents the analysis.

\section{Zwarts (2005) on to-PPs}

We adopt Zwarts's (2005) account of spatial to-PPs, which aims to capture the traditional view that in combination with a motion verb, the reference object (or goal) denoted by the NP of the to-PP is reached. In Zwarts's approach, a directional PP denotes a set of paths, where a path $p$ is defined (p. 748) as a continuous function from the real unit interval $[0,1]$ to positions in some model of space. For a path $p$, the starting point of $p$ is $p(0)$, its end point is $p(1)$, and for any $i \in[0,1], p(i)$ is the corresponding point or position of $p$. Paths are partially ordered by a subpath relation: path $p$ is a subpath of path $q(p \leq q)$ if $p$ is the same path as $q$ restricted to part of $q$ 's domain. In addition, two paths $p$ and $q$ can be concatenated if the end point of $p$ is the same position as the starting point of $q$, in which case, $p+q$ is the concatenation of $p$ and $q$. (If this condition isn't fulfilled, then $p$ and $q$ cannot be concatenated, so concatenation is a partial operation on paths.) Finally, if an event $e$ is a motion event, the trace of $e$ is the path followed by the theme or agent of $e$. (3)-(5) show how Zwarts derives (p. 756) the VP walk to the station (his original notation slightly modified):

(3) a. [PP to the station] $\rightsquigarrow \lambda p \cdot p(1)=$ location(the-station)

b. $[\mathrm{v}$ walk] $\rightsquigarrow \lambda e$.walk $(e)$ 
(4) $[\mathrm{vP} \mathrm{VPP}] \rightsquigarrow \lambda e . V(e) \wedge \operatorname{trace}(e)=p \wedge P(p)$

(Where $V$ and $P$ are the predicates corresponding to $\mathrm{V}$ and PP, respectively)

(5) [vp walk to the station] $\rightsquigarrow$

$\lambda e \cdot \operatorname{walk}(e) \wedge \operatorname{trace}(e)=p \wedge p(1)=$ location(the-station)

The analysis in (5) captures the traditional view that a to-PP in combination with a motion verb designates a reference object or goal (here: the station) that is reached.

In Zwarts's approach (p. 753), a directional PP may be unbounded or bounded. A directional PP is unbounded just in case it has cumulative reference, and it is bounded just in case it lacks cumulative reference. A set of paths $X$ is cumulative iff (p. 751): (i) there are $p, q \in X$ such that $p+q$ exists and (ii) for all $p, q \in X$, if $p+q$ exists, then $p+q \in X$. A to-PP is bounded because it lacks cumulative reference: no two paths in the denotation of a to-PP can be concatenated and still yield a to-PP of the same type. (In contrast, a towards-PP is unbounded because it has cumulative reference.) In (5), the boundedness of to the station in combination with walk yields a VP that is bounded, as shown by the conventional judgment of compatibility with a time-span adverbial and of incompatibility with a durative adverbial:

(6) Moritz walked to the station in ten minutes/\#for ten minutes.

\section{Too strong a meaning for to}

A first problem for the traditional view is that VPs formed with motion verbs and to/zu-PPs may be unbounded (i.e., have cumulative reference). Native speakers of English seem to routinely accept sentences similar to (6) with a durative adverbial. Furthermore, durative for-adverbials are not difficult to find with English motion verbs combined with to-PPs in corpora (examples are taken from the Internet):

(7) a. We walked to the steps for approximately 30 minutes, of course, it took us two hours considering that we stopped in almost every single store to look at the clothes.

b. It was sunny when I left the hostel in Taitung and biked to the train station for 20-40 minutes.

c. I walked to Karumo dispensary for two hours.

Durative adverbials can modify VPs built with a manner-of-motion verb and a $z u$-PP in German as well: ${ }^{1}$

1 Lukassek, Prysłopska, Hörnig \& Maienborn (2017) conducted an acceptability judgment task and 
A new case of low modality: Goal PPs

(8) Ein junger Mann in den USA ist sieben Stunden lang zu Fuß zur Arbeit gelaufen, weil sein Auto zuvor kaputt gegangen war.

(Internet)

'A young man walked to his workplace for seven hours because his car broke down.'

A second problem for the traditional view is that the inference that the goal is reached seems implicated rather than entailed, which is also unexpected if $t o / z u$-PPs denote paths which end at the reference object:

(9) a. At eight, John walked to the next city, but he was so weak he had to give up before he could get there.

b. 'Payton! My God! I found her! Here ... She's here!' Dell ran to her, but before he could even get close to her, he [...]

(Internet)

c. She ran to her but she could never seem to get any closer.

(Internet)

d. We went to an exhibition, but never arrived.

(Internet)

(10) Am Nachmittag ist Hans zum anderen Ende der Stadt geradelt, aber auf halbem Weg ist er dann umgedreht.

'In the afternoon, Hans biked to the other end of the city, but half way he turned back.'

Nakazawa (2006) already observed that in English, Japanese and Korean, a nonprogressive sentence with $g o$ (or its Japanese/Korean counterpart) easily allows the cancellation of the inference that the goal is reached, by contrast with come:

(11) He \#came / OK went to [the] school at eight, but he hasn't arrived yet.

a self-paced reading study on sentences such as (ia) below, and found out that such sentences took longer to read and were less acceptable than sentences with an aspectually ambiguous PP (e.g., über die Nordse 'over the North Sea'). This seems to contradict our claim that German $z u$-PPs are compatible with durative adverbials. We think, however, that the results they obtain for sentences such as (ia) are due to the fact that the durative adverbial appears after a clause boundary. For us, (ib) is more acceptable than (ia), and also does not trigger the inference that the pirate reached the North Sea (while the first clause of (ia) does). These differences between (ia) and (ib) can be explained as follows. The modified VP can have both telic and atelic uses; however, the telic use is preferred by default (for it conveys a stronger meaning), and this preferred telic reading is much more difficult to cancel after a clause boundary than before (Bott 2010, Bott \& Hamm 2014).

(i) a. Der Pirat segelte zur Nordsee, und zwar drei Tage lang.

'The pirate sailed to the North Sea, and for three days in fact.'

b. Der Pirat segelte drei Tage lang zur Nordsee.

'The pirate sailed to the North Sea for three days.' 
Martin, Grant, Piñón and Schäfer

\section{The experiments}

\subsection{Material and methodology}

To assess the strength of the inference that the goal is reached triggered by nonprogressive sentences built with a motion verb and a goal-PP, we ran a questionnaire in German and English probing participants' level of certainty that the critical referent arrived at their destination. We manipulated two variables. (i) VERB TYPE: manner (laufen 'walk') vs. deictic verbs of motion ('come/go' in English; kommen only in German, given the ambiguity of gehen 'walk/go'), and (ii) presence or absence of a clause introducing an event that could introduce DOUBT that the goal was reached. This clause introduces an event that could have prevented the path from being completed, but critically did not exclude that the path was completed. VERB-TYPE was manipulated within participants and within items. DOUBT was manipulated between groups to avoid pushing the without-doubt conditions to ceiling, potentially neutralising an underlying difference between verb types. ${ }^{2}$

For Experiment 1, we recruited 80 native speakers of German via Prolific Academic; 4 participants were excluded due to self-reported non-native speaker status and 5 on analysis of anchor fillers (described below). We built 12 experimental items; 2 additional items were excluded because they used other prepositions than $z u$ (e.g., in die Küche 'in the kitchen'). We used 10 different manner-of-motion verbs (fahren, hüpfen, klettern, laufen, marschieren, rennen, schleichen, spazieren, stapfen, tänzeln and one deictic verb (kommen). For Experiments 2 and 3, we recruited 40 and 41 native speakers of English in the USA via Prolific Academic. On the basis of the analysis of anchor fillers, we excluded 10 participants for further analyses for Experiment 2, and 3 for Experiment 3. We used 14 experimental items (roughly the same as for Experiment 1 on German), with 9 different manner-of-motion verbs (bike, climb, dance, hop, run, skip, tiptoe, trudge, walk). As for deictic verbs, Experiment 2 used go, and Experiment 3 come.

Examples of German and English test items are given in (12)-(13). The DOUBT clause in $(12 b) /(13 b)$ appeared in the DOUBT condition only. The present perfect was used across German items (both test sentences and questions), and the simple past in English. All experimental items had an (intentional) agentive subject.

(12) a. Nina is a heavy smoker. At three o' clock in the morning she walked/went to the convenience store on the next street over...

b. DOUBT-clause:

... but on the way she ran into good friends at the bus stop.

2 The experimental material and all other data can be consulted at the following page: https: //implicature.xyz/ fmartin/salt30.html 
A new case of low modality: Goal PPs

c. QUESTION: 'How safely can you conclude that Nina reached the convenience store?'

a. Gestern hatte Paul eine Matheprüfung, aber er war Yesterday have.SP.3SG Paul a math exam but he be.SP.3SG nicht gut vorbereitet. Er ist mit dem Fahrrad zur Schule not well prepared he is with the bike to-the school gefahren/gekommen ... driven/come

'Yesterday Paul had a math test but he was not well-prepared. He biked/ came to the school ...'

b. DOUBT-clause:

... aber auf dem Weg hat er ein Paar gute Freunde getroffen, but on the way has he a couple good friends met

die auf dem Weg zum Schwimmbad waren. who on the way to-the swimming-pool were

'... but on the way he met a couple of good friends who were on their way to the swimming pool.'

c. QUESTION:

Wie sicher können Sie schlussfolgern, dass Paul die Schule erreicht how sure can you conclude that Paul the school reached hat?

has

'How safely can you conclude that Paul reached the school?'

The questionnaire required participants to rate how safely they could conclude from the test sentence that the DP's location was reached by the agent of the motion event on a scale from 1 (not at all safely) to 7 (very safely). The experiment was presented using IbexFarm (Drummond, ms.). The question and rating scale were presented directly under the critical sentence, and there was no time limit to respond. The experiment took approximately about half an hour to complete. Experimental items were intermixed with filler items. Some of these fillers were from unrelated experiments, and some served to anchor the scale at its endpoints, as seen in (14). For Experiment 3, we constructed some fillers so as to assess the impact of the DOUBT but-clause when the inference is by assumption entailed, as seen in (15).

(14) a. HIGH ANCHOR: The chef stabbed the aggressive and unruly waiter in the restaurant kitchen while the customers started to leave.

QUESTION: How safely can you conclude that the chef used a knife? 


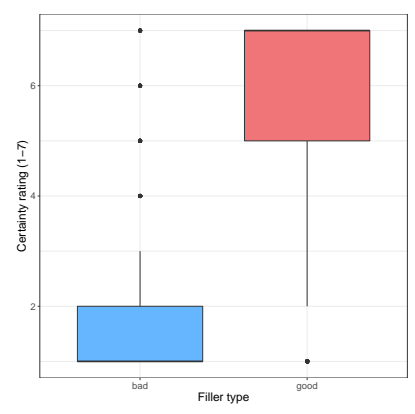

(a) Exp. 1 (German)

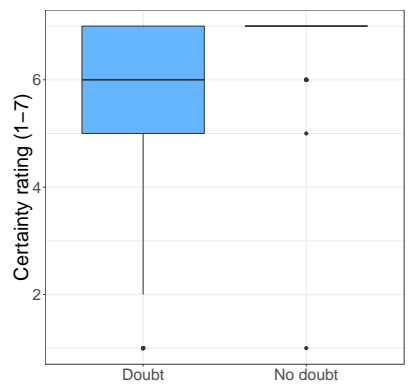

(b) Exps. 2-3 (English, with and without DOUBT)

Figure 1 Experiments 1-3: results for low/high anchors fillers

b. LOW ANCHOR: The politician declined to speak to any New York Times journalist except Dorothy.

c. QUESTION: How safely can you conclude that Dorothy is a politician?

(15) a. HIGH ANCHOR: Rita burned all the letters she received from Paul...

b. DOUBT-clause: ... but while she was doing it she realized these letters might be of good use after all.

c. QUESTION: How safely can you conclude that the letters Rita received from Paul got burnt?

German and English anchor fillers (each time 28 items) showed expected results, as shown in Figure 1a-1b. These were used also as an exclusion criterion (less than 2 points difference on average led to exclusion from further analyses).

\subsection{Results}

Figure 2 shows mean ratings per condition for each experiment. For all analyses, we used Cumulative Link Mixed-effects Models (CLMM) implemented in the ordinal package in $\mathrm{R}$ (Christensen 2019). The fixed effects contrasts for VERB TYPE and DOUBT were sum-coded. Table 1 shows the model parameters. For all experiments, participants in the doubt condition could less safely conclude that the goal was reached. However, the VERB TYPE effect was not uniform across experiments. In German, participants were less certain that the goal was reached with manner-ofmotion verbs as compared to kommen. Follow-up models on a subset of the data showed that this effect held when examining the DOUBT conditions only $(z=-4.786$, $p<.0001)$ and also when examining the NO DOUBT conditions only $(z=-5.234$, $p<0.0001)$. For English, VERB TYPE did not play a significant role in certainty ratings when the deictic verb was go (Experiment 2) but was significant when the 
A new case of low modality: Goal PPs

Formula:

Response $\sim$ Verb Type $*$ Doubt $+(1+$ Verb Type $\mid$ Participant $)+(1+$ Verb Type $*$ Doubt | Item)

Experiment 1 (German kommen)

VERB TYPE

$\begin{array}{rrrr}\text { Estimate } & \text { SE } & Z & p \\ -1.199 & 0.193 & -6.222 & <0.0001 \\ 1.167 & 0.191 & 6.123 & <0.0001 \\ -0.133 & 0.147 & -0.907 & 0.364\end{array}$

DOUBT

VERB TYPE * DOUBT

Experiment 2 (English go)

VERB TYPE

$\begin{array}{rrrr}\text { Estimate } & \mathrm{SE} & Z & p \\ -0.064 & 0.010 & -0.638 & 0.523 \\ 1.566 & 0.349 & 4.490 & <0.0001 \\ -0.020 & 0.098 & -0.201 & 0.841\end{array}$

DOUBT

VERB TYPE* DOUBT

Experiment 3 (English come)

VERB TYPE

$\begin{array}{rrrr}\text { Estimate } & \mathrm{SE} & Z & p \\ -0.872 & 0.185 & -4.720 & <0.0001 \\ 1.370 & 0.337 & 4.063 & <0.0001 \\ 0.074 & 0.154 & 0.481 & 0.631\end{array}$

VERB TYPE * DOUBT

Table 1 CLMM Model parameters for Experiments 1-3

deictic verb was come (Experiment 3). Although the interaction between VERB TYPE and DOUBT was not significant for Experiment 3, numerically the difference between verb types was greatest when the doubt clause was present. When examined separately the effect of VERB TYPE was significant for doubt $(z=-3.762, p<0.001)$ and no doubt $(z=-3.413, p<0.001)$ conditions in Experiment 3.

The overall pattern of results (summarized in the box plots in Figure 3 ) shows that the presence of DOUBT has a negative impact on participants' certainty that the goal has been achieved. This effect is present for manner verbs and deictic verbs across languages. Whether ratings also depended on VERB TYPE varied according to the language and the specific deictic verb used. While we leave statistical analyses across languages for future work, we note that numerically, ratings for kommen were lower than for come in both conditions. In summary, the results suggest that the inference that the goal is reached is defeasible with manner verbs and English go, with numerical suggestion that the inference is less defeasible with come-verbs. 
Martin, Grant, Piñón and Schäfer

\begin{tabular}{lrrlrrlrr}
\hline & $-\mathrm{D}$ & $+\mathrm{D}$ & & $-\mathrm{D}$ & $+\mathrm{D}$ & & $-\mathrm{D}$ & $+\mathrm{D}$ \\
Manner & 4.88 & 3.29 & Manner & 5.73 & 3.90 & Manner & 6.00 & 3.86 \\
kommen & 6.22 & 4.69 & go & 5.88 & 3.97 & come & 6.60 & 4.99 \\
Difference & -1.34 & -1.40 & Difference & -0.15 & -0.07 & Difference & -0.60 & -1.13 \\
(a) Exp. 1 (German) & & (b) Exp. 2 (English) & & (c) Exp. 3 (English) &
\end{tabular}

Figure 2 Experiments 1-3: results for test items ('D' stands for DOUBT)

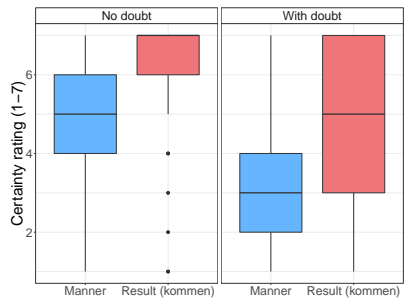

(a) Exp. 1 (German)

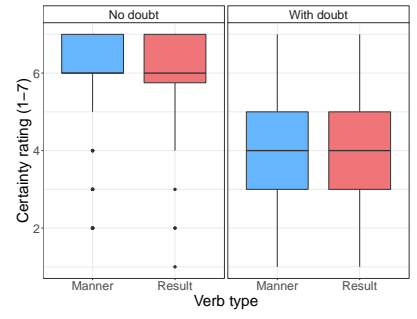

(b) Exp. 2 (English)

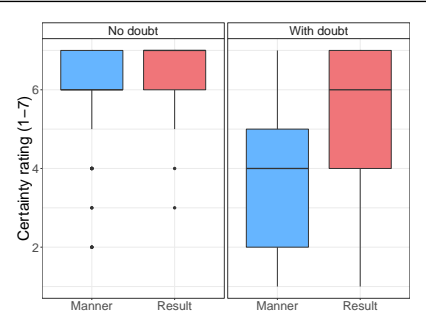

(c) Exp. 3 (English)

Figure 3 Box plots for manner and deictic verbs, Experiments 1-3

\section{The analysis}

\subsection{The modal meaning of $t o / z u$}

The modal teleological notion of goal is often recruited in the characterization of to - to-PPs are often called 'goal PPs', 'goal-oriented PPs', 'PPs with directed goal interpretations', etc. - but is not represented in the semantics of to. Our proposal is to express this meaning in the semantics of $t o / z u$. However, $t o / z u$-PPs are not only compatible with agents pursuing goals, but also with accidental agents and inanimates. ${ }^{3}$ Furthermore, a link seems to exist between the defeasibility of the culmination inference and the presence of an intentional agent, as observed in other contexts (see Martin \& Schäfer 2012). For instance, the inference that the goal is reached is defeasible in (16)-(17) when the subject's referent is an intentional agent, but seems entailed when it is not. ${ }^{4}$ The challenge is to capture these facts

3 Haselbach (2013), who also proposes that $z u$ has a modal meaning, argues that $z u$ is odd in nonintentional contexts on the basis of contrast such as Die Meise flog zum Vogelnest/?Elektrozaun 'The chikadee flew to the birdnest/ electric nest'. We do no think, however, that $z u$ requires an intentional agent, as examples in (17) also show.

4 Note that (16b) seems more acceptable on an irrelevant reading where unknowingly or accidentally is not used to signal lack of agentivity, but rather a de dicto reading of the NP in the PP. Under this reading, Berlin is not interpreted relative to the global context, but according to the agent's beliefs. The subject's referent may thus intentionally drive to a city that he mistakenly takes to be Berlin. The de dicto reading of the NP denoting the reference object also appears with PPs denoting paths that 
A new case of low modality: Goal PPs

without positing an ambiguity for $t o / z u$, for which we lack independent evidence (in particular, we are not aware of any language lexicalizing goal-PPs differently depending on the thematic role of the subject).

(16) a. This morning Ziggy drove to Berlin, but he never actually arrived there.

b. This morning Ziggy accidentally/ unknowingly drove to Berlin, \#but he never actually arrived there.

c. The pirate sailed to the island, but he never arrived there.

d. The Mary Celeste sailed to the island, \#but it never arrived there.

e. She ran to him but she could never seem to get any closer.

f. She accidentally/ unknowingly ran to him \#but she could never seem to get any closer.

(17) a. Die Pilotin ist zur Insel geflogen, aber sie kam dort nie an.

'The pilot flew to the island, but she never arrived there.'

b. Die Luftballons sind zur Insel geflogen, \#aber sie kamen dort nie an. Intended: 'The balloons flew to the island, but they never arrived there.'

c. Der Pirat schwamm zur Insel, aber er kam dort nie an. 'The pirate swam to the island, but he never arrived there.'

d. Die Blätter schwammen zum Abfluss, \#aber sie kamen dort nie an. Intended: 'The leaves swam to the drain, but they never arrived there.'

e. Heute Morgen ist Ziggy (\#versehentlich/unbewusst) zu seiner Tante (in Berlin) gefahren, aber er kam dort nie an.

'This morning Ziggy (accidentally/unknowingly) drove to her aunt (in Berlin, but he never arrived there.'

In this section, we argue that the prepositions $t o / z u$ are modal prepositions, whose flavor varies with the type of subjects. We focus on English data, but believe the analysis covers German $z u$ as well. In section 5.2, we account for the contrast between intentional vs. accidental agents (or themes). In section 5.3, we trace the verb-type effect back to an aspectual difference between come-verbs on one hand and $g o$ and manner-of-motion verbs on the other. In section 5.4, we look at the differences between German and English.

We propose that to encodes a necessity modal that quantifies over $\alpha$-worlds, while the type of subjects determines the value $\alpha$ may have, as shown in section 5.2. ${ }^{5}$

clearly have the location of the reference object as their endpoint (e.g., into-PPs), and is therefore tangential to the modal meaning of goal-PPs.

$5 \mathrm{To} / z u$ also have a modal meaning used as infinitive markers, e.g., Ziggy did it to win, Es ist zu machen 'It is to be done', etwas zu lesen 'something to read' (see Gronemeyer 2001, Holl 2010), Es ist zum Heulen schön 'It is so beautiful that you have to cry' (Ermakova, Lukassek \& Nau 2020). Fischer (1997) points out that in English, to-infinitives regularly occur with what she calls 'irrealis 
In the $\alpha$-worlds quantified over by the modal, the asserted event $e$ has an extension event $e^{\prime}$ which shares the same $\theta$-participants as $e$ and whose path has the reference object as its end point, as in (18), where $\oplus$ is the mereological sum operation, and $\theta$ stands for a thematic relation.

$$
\begin{aligned}
& \text { to Berlin } \rightsquigarrow \lambda V \lambda \theta \lambda x \lambda e \lambda p \lambda w . V_{w}(e) \wedge \theta_{w}(x, e) \wedge \operatorname{trace}(e)=p \wedge \\
& \exists q\left[p \leq q \wedge q(1)=\operatorname{location}_{w}(\text { berlin }) \wedge\right. \\
& \left.\square \alpha_{\alpha_{w}}^{w^{\prime}}\left(\exists e^{\prime}\left[V_{w^{\prime}}\left(e^{\prime}\right) \wedge \theta_{w^{\prime}}\left(x, e^{\prime}\right) \wedge \operatorname{trace}\left(e \oplus e^{\prime}\right)=q\right]\right)\right]
\end{aligned}
$$

Applied to an event predicate $V$, (18) yields a set of paths $p$ which serve as traces of events $e$ of type $V$ having $x$ as a $\theta$-participant, which are parts of some path $q$ that ends at the location of Berlin, and such that in all $\alpha$-worlds $w^{\prime}$ accessible from $w$, there is an extension event $e^{\prime}$ of type $V$ in $w^{\prime}$ of event $e$ in $w$ such that the trace of $e \oplus e^{\prime}$ is the path $q$ and such that $x$ is a $\theta$-participant to $e^{\prime}$.

Once the PP is combined with the verb drive and the Voice head in (19b) introducing an (intentional or accidental) agent, we obtain (19c) as the meaning of the bare predicate used in the first clause of $(16 \mathrm{a} / \mathrm{b})$ (ignoring the contribution of the adverbial in (16b)).

$$
\begin{aligned}
& \text { a. drive to Berlin } \rightsquigarrow \lambda \theta \lambda x \lambda e \lambda p \lambda w \text {.drive }{ }_{w}(e) \wedge \theta_{w}(x, e) \wedge \operatorname{trace}(e)=p \wedge \\
& \exists q\left[p \leq q \wedge q(1)=\text { location }_{w}(\text { berlin }) \wedge\right. \\
& \left.\square_{\alpha_{w}}^{w^{\prime}}\left(\exists e^{\prime}\left[\operatorname{drive}_{w^{\prime}}\left(e^{\prime}\right) \wedge \theta_{w^{\prime}}\left(x, e^{\prime}\right) \wedge \operatorname{trace}\left(e \oplus e^{\prime}\right)=q\right]\right)\right] \\
& \text { b. Voice } \rightsquigarrow \lambda x \lambda e \lambda w \text {.agent }{ }_{w}(x, e) \\
& \text { c. Ziggy Voice drive to Berlin } \rightsquigarrow \\
& \lambda e \lambda p \lambda w \text {. } \operatorname{drive}_{w}(e) \wedge \text { agent }_{w}(\text { ziggy, } e) \wedge \operatorname{trace}(e)=p \wedge \\
& \exists q\left[p \leq q \wedge q(1)=\text { location }_{w} \text { (berlin) } \wedge\right. \\
& \left.\square_{\alpha_{w}}^{w^{\prime}}\left(\exists e^{\prime}\left[\operatorname{drive}_{w^{\prime}}\left(e^{\prime}\right) \wedge \operatorname{agent}_{w^{\prime}}\left(\text { ziggy, } e^{\prime}\right) \wedge \operatorname{trace}\left(e \oplus e^{\prime}\right)=q\right]\right)\right]
\end{aligned}
$$

The meaning in (18) captures the intuition that to encodes an end point, in contrast to towards/ auf ...zu: in (18), the extension events $e^{\prime}$ in $\alpha$-worlds have a bounded path as their trace. However, it also accounts for the defeasibility of the inference that this end point is reached: since the base world $w$ is not necessarily an $\alpha$-world, the reference object does not necessarily have to be reached in $w$.

Given the meaning in (18), we can also show that to/zu-PPs may have cumulative reference (i.e., be unbounded): for a value of $V$, assuming that the path predicate to Berlin denotes at least two paths whose concatenation exists, then the concatenation of any two paths that can be concatenated yields a to-PP of the same type. The event

directive/potential' verbs (e.g., promise), but not with 'realis' verbs (e.g., confirm). See Los (2005) on the diachronic link between the prepositional and infinitival to, and Haspelmath (1989) on the connection between the modal meaning of the infinitive and the allative meaning of $t o / z u$. 
predicate corresponding to (e.g.) the VP drive to Berlin thus also has cumulative reference, which accounts for the compatibility of a durative adverbial.

However, we also account for the fact that to/zu-PPs may have quantized reference. If the denotation of to Berlin is contextually restricted so as to describe paths $p$ which are identical to some $q$ path ending at the location of Berlin, there are no two paths in the denotation of to Berlin whose concatenation exists, and the to-PP is thus bounded. Obviously, if the denotation of to Berlin is contextually restricted so that any $p=q$ and the predicate has quantized reference, the inference that the goal is reached cannot be canceled anymore, as seen in $(20 \mathrm{a} / \mathrm{b})$.

(20) a. This morning Ziggy drove to Berlin in two hours, \#but he was so sick he had to stop driving before he could arrive there.

b. Heute früh ist Hans in einer Stunde zum anderen Ende der Stadt geradelt, \#aber auf halbem Weg ist er dann umgedreht.

Intended: 'This morning Hans biked to the other end of the city in an hour, but halfway he decided to go back.'

Finally, we make the additional assumption that in the absence of information to the contrary, the asserted path $p$ is identified with some $q$ ending at the reference object. Given this assumption, we account for why the inference that the goal is reached is implicated in the first place in the absence of a DOUBT-clause (with an intentional agent in subject position). We see two sources for this implicature. Firstly, when $p=q$, (18) has a stronger meaning (if $p=q$, then $p \leq q$, but the reverse does not hold). Secondly, to/zu compete with towards in English and auf...zu/ Richtung in English, which we take to denote proper parts of some path ending at the reference object (and thus never ending themselves at the reference object): ${ }^{6}$

6 That towards-PPs denote proper parts of some path ending at the reference object (beyond entailing that $p(1)$ is nearer to the reference object than $p(0)$, as proposed by Zwarts 2005) accounts for their robust incompatibility with time-span adverbials. Note that following (18) and (21), to-PPs do not asymetrically entail towards-PPs, which is confirmed by the acceptability of, for instance, Ziggy is driving to Berlin, although right now he's not driving towards Berlin. The following sentences show that towards-PPs (or auf...zu-PPs and in Richtung-PPs in German) and to-PPs (or zu-PPs in German) are on the same scale, with $t o / z u$-PPs being the stronger alternative (despite not entailing towards-PPs). See Hirschberg (1991) on scales whose order relations are not relations of entailment.

(ii) a. Hans ist nicht nur in RICHTUNG der Polizeistation gegangen, er ist ZUR Polizeistation gegangen.

Er ist nicht nur auf die Polizeistation ZUgegangen, er ist ist ZUR Polizeistation gegangen.

b. Hans didn't only go TOWARDS the police station, he went TO the police station. 
towards Berlin $\rightsquigarrow \lambda p \cdot p(1)$ is nearer to location(berlin) than $p(0) \wedge$ $\exists q[p<q \wedge q(1)=$ location(berlin) $]$

\subsection{The subject effect}

This section addresses the question of why a subject referring to an intentional agent seems to be necessary in order to cancel the inference that the goal is reached, as the contrasts in (16)-(17) partly repeated below illustrated. Observe that the first clause of (16a) preferably offers a prospective perspective on the event (i.e., it is viewed from its initial part), while the first clause of (16b) preferably offers a retrospective perspective on the event (i.e., it is viewed from the arrival).

(16) a. This morning Ziggy drove to Berlin, but he never actually arrived there.

b. This morning Ziggy accidentally/ unknowingly drove to Berlin, \#but he never actually arrived there.

Following the strategy adopted by Martin \& Schäfer (2012) for defeasible causative verbs, we assume that the type of subjects (intentional agent vs. accidental agent or theme) determines the value $\alpha$ can have (i.e., the set of worlds the modal ranges over), as seen in (22).

Conditions associated with to Berlin:

a. to-berlin $(\alpha, V, \theta, x, e, p, w) \wedge \theta=$ int-agent $\rightarrow$ $\alpha=$ teleological

(The presence of an intentional agent implies a teleological modal base)

b. to-berlin $(\alpha, V, \theta, x, e, p, w) \wedge(\theta=$ accid-agent $\vee \theta=$ theme $) \rightarrow$ $\alpha=$ circumstantial

(The presence of an accidental agent or a theme implies a circumstantial modal base)

If the subject's referent is an intentional agent, the modal base is teleological: it contains the worlds where the intention that the agent entertains in $w$ while performing the asserted event is realized. Since the evaluation world $w$ is not necessarily included in the teleological modal base, the intention does not necessarily have to be fulfilled in $w{ }^{7}$ Furthermore, if $w$ is included in the teleological modal base such that the agent does actually realize their intention to reach the reference object in $w$, the

7 An inanimate entity may in some contexts be interpreted as metonymically standing for an intentional agent. Take for instance (i) below, suggested to us by B. Lowell-Sluckin, under the reading where the temporal adverbial locates the departure rather than the arrival of the boat: 
A new case of low modality: Goal PPs

semantics of to in (18) leaves open the possibility that the destination is reached after the reference time only. This is correct, as (23a) shows. In this example, the event $e$ asserted in the first clause is temporally included in the reference time given by this morning (since the simple past is used). But the event $e^{\prime}$ in the scope of the modal may take place after the reference time (precisely because $e^{\prime}$, when so interpreted as an extension event, takes place after $e$ ). This is the reason why (23a) offers a prospective perspective on the event (the asserted event $e$ is an initial non-final part of the sum event $e \oplus e^{\prime}$ ending in Berlin). (23b) gives the meaning of the first clause of (23a).

(23) a. This morning Ziggy drove to Berlin. He arrived at 4 p.m.

b. This morning Ziggy Voice drove to Berlin $\rightsquigarrow$

$$
\begin{aligned}
& \lambda e \lambda p \lambda w \text {.drive }{ }_{w}(e) \wedge \text { int-agent }_{w}(\text { ziggy, } e) \wedge \operatorname{trace}(e)=p \wedge \\
& \tau(e) \subseteq \text { this-morning } \wedge \\
& \exists q\left[p \leq q \wedge q(1)=\text { location }_{w}(\text { berlin }) \wedge^{\prime}\right. \\
& \square_{\alpha_{w}}^{w^{\prime}}\left(\exists e ^ { \prime } \left[\operatorname{drive}_{w^{\prime}}\left(e^{\prime}\right) \wedge \text { int-agent }_{w^{\prime}}\left(\text { ziggy, } e^{\prime}\right) \wedge\right.\right. \\
& \left.\left.\left.\operatorname{trace}\left(e \oplus e^{\prime}\right)=q\right]\right)\right]
\end{aligned}
$$

However, when to Berlin has quantized reference (as it does in the presence of a time-span adverbial, as in the first clause of (24) below), the asserted path $p$ is identified with some $q$ ending in Berlin, as seen in the previous section. Ziggy must therefore arrive this morning, too, as the second clause of (24) shows.

(24) This morning Ziggy drove to Berlin in one hour. \#He arrived at 4 p.m.

In the first clause of (24), the asserted event $e$ is identified under the most plausible reading with the sum event $e \oplus e^{\prime}$ in (18). And if $e=e \oplus e^{\prime}$, then $e=e^{\prime}$; i.e., $e^{\prime}$ loses its role of extension event and the modality ends up trivialized.

Let us now turn to the case where the subject's referent is not an intentional agent, i.e., is a theme or an accidental agent. In that case, the modal base is circumstantial: it contains the set of worlds compatible with some circumstances in the world of evaluation $w$. Since the world of evaluation shares all circumstances with itself, it is in the domain of the necessity modal (see also Alonso-Ovalle \& Hsieh 2018). This explains why the goal has to be reached in $w$ with such subjects. Thus for instance, the first clause of (25a) receives the meaning in (25b).

(i) The empty boat, whose crew all died during the voyage, sailed to the island on October $3 \mathrm{~d}$.

The context of (i) indicates that the asserted sailing event $e$ involved an intentional agent. We take this to be the reason why (i) so interpreted leaves open whether the boat actually arrived at destination. 
(25) a. This morning Ziggy accidentally drove to Berlin. \#He arrived at 4 p.m.

b. This morning Ziggy accidentally Voice drove to Berlin $\rightsquigarrow$

$$
\begin{gathered}
\lambda e \lambda p \lambda w . \text { drive }_{w}(e) \wedge \text { accid-agent }_{w}(\text { ziggy }, e) \wedge \operatorname{trace}(e)=p \wedge \\
\tau(e) \subseteq \text { this-morning } \wedge \wedge \\
\exists q\left[p \leq q \wedge q(1)=\text { location }_{w}(\text { berlin }) \wedge\right. \\
\square \\
\square_{\alpha_{w}}^{w^{\prime}}\left(\exists e ^ { \prime } \left[\text { drive }_{w^{\prime}}\left(e^{\prime}\right) \wedge \text { accid-agent }_{w^{\prime}}\left(\text { ziggy }, e^{\prime}\right) \wedge\right.\right. \\
\left.\left.\left.\operatorname{trace}\left(e \oplus e^{\prime}\right)=q\right]\right)\right]
\end{gathered}
$$

However, while (25b) together with the conditions in (22) (and the assumption that $w$ is always included in the circumstantial modal base) account for why (25a) entails that Ziggy actually arrived in Berlin, it does not explain yet why the first clause of (25a) strongly suggests that he did so this morning (and not later, as the oddity of second clause of (25a) indicates). ${ }^{8}$ For (25b) does not require the extension event $e^{\prime}$ to be included in the reference time. The oddity of (25a) seems to indicate that just like in (24), the asserted event $e$ itself is understood as ending in Berlin (and that the trace $p$ of $e$ is identified with some $q$ ending in Berlin). Why is this so?

We propose that the problem of (25a) is of the same nature as the problem of (24). That is, the inference that the asserted event $e$ itself ends in Berlin (rather than some modal extension event $e^{\prime}$ taking place after $e$ ) arises because the VP drive to Berlin receives a telic interpretation in the presence of the adverb accidentally. This is supported by the fact that drive to Berlin loses its compatibility with a for-adverbial when the subject is an accidental agent, as shown by the contrast in (26):

(26) This morning Ziggy (intentionally/\#accidentally drove to Berlin) for an hour.

But why is it that the telic interpretation of such VPs is enforced when the subject is an accidental agent (or theme)? Why do we draw the inference that the 'accidental' asserted event $e$ itself ends in Berlin, whereas the semantics leaves open the possibility that $e$ does not end in Berlin?

We believe that this inference reflects how (non-)intentionality interacts with a general epistemic constraint bearing on partitive uses of telic predicates, as previously observed for progressive telic sentences and non-culminating accomplishments (see Naumann \& Piñón 1997, Zucchi 1998, Varasdi 2014 on progressive sentences with intentional vs. non-intentional subjects, Martin 2015 on non-culminating accomplishments). Take for instance Mittwoch's (1988) sentence \#The level of the lake was rising 10 feet when I arrived. For Zucchi (1998), this sentence is infelicitous because "normally, if a lake is rising at a given moment, we cannot determine

8 The intended reading of (25a) excludes the possibility of an inchoative reading of drove (interpreted as left/set off to drive). Such a reading of drove is not possible in the presence of a time-span adverbial, which explains why (25a) appears more acceptable than (24). 
whether the lake will rise 10 feet by looking at the rising activity at that moment or at the circumstances surrounding the activity at that moment' (p. 205). It becomes felicitous only once we know that the level of the lake ultimately rose 10 feet. In Varasdi's (2014) terms, infelicity arises because normally, the event in progress is not indicative, in the set of contextually given alternatives, of the event type denoted. With an intentional agent, such problems normally do not arise, for 'intention together with an appropriate activity geared toward realizing the goal is a proxy for the actual realization of the goal' (Martin 2015: 257). ${ }^{9}$ We propose that the same indicativity requirement must be fulfilled by the event asserted by simple past sentences built with a motion verb and a goal-PP. For us, interpreting the asserted event $e$ as ending at the reference object with an accidental agent or a theme is the most natural way to fulfill this requirement: it is only when the asserted event $e$ ends at the reference object that we have enough ground to assert that the trace $p$ of $e$ is a part of some path $q$ ending at the reference object. Hence also why sentences such as Ziggy accidentally drove to Berlin offers a retrospective perspective on the event: we consider them from the arrival because 'there is typically no knowledge of involuntary actions until they have been completed' (Fauconnier 2012: 131). Thus for instance, (25a) is not acceptable because normally, Ziggy's driving $e$ does not have properties that allow one to know that the path $p$ of his driving is a part of some path $q$ ending in Berlin before this path $p$ ends itself in Berlin - how could we know where he will ultimately end up before he does so? The oddity of the second clause in (27) below has the same source: on which ground can we assert that the empty boat is sailing along a path $p$ which is a part of some path $q$ ending at the island before it arrives there? Precisely because warrants for asserting the first clause of (27) are missing before the boat reaches the island, the hearer infers that the asserted event $e$ does end at the island (and consequently, the arrival is understood as temporally included in the reference time given by this morning).

(27) This morning an empty boat sailed to the island. \#It arrived in the early afternoon.

By contrast, (23a) is acceptable because Ziggy's intentional driving event $e$ is indicative of Ziggy's driving to Berlin even before he reaches his destination.

9 However, even with an intentional agent, infelicity may arise if the intention is impossible to realize. A famous example is Landman's (1992) sentence Mary was swimming across the Atlantic ocean. Interestingly, the same indicativity condition must also be fulfilled by the event denoted by nonprogressive sentences with a manner-of-motion verb and a to-PP: as Jad Wehbe (p.c.) observes, Mary swam to the other side of the ocean is not felicitous if the speaker doesn't know that Mary succeeded, and this despite of the fact that, like its progressive counterpart, it does not entail that Mary reaches the other side of the ocean. Infelicity arises for the same reason as in Landman's sentence: following the default assumptions, Mary's attempt is destined to fail and thus cannot be indicative of her swimming to the other side of the ocean. 
Martin, Grant, Piñón and Schäfer

\subsection{The verb-type effect}

The results reported in section 4 suggest that the inference that the goal is reached is defeasibly implicated with manner-of-motion verbs as well as with go in English, but is very similar to an entailment with come. Suggestive for this conclusion is that while the mean response for come is 4.99 in the DOUBT-condition, the modal response - the one chosen the most often - is actually 7.

To explain this, we question the common view that come and go have exactly the same assertive meaning and only differ by the indexical presupposition. ${ }^{10} \mathrm{We}$ propose that go is an all-purpose, highly underspecified motion verb, while comeverbs are achievements (as also proposed by Heyde-Zybatow 2008 for German kommen). Firstly, with to/zu-PPs, come-verbs do not yield VPs with cumulative reference, as reflected by their incompatibility with durative adverbials, as seen in $(28 \mathrm{a} / \mathrm{b})$ (the result-state oriented reading is ignored for the judgments). Secondly, combined with a goal-PP, kommen/come cannot express a partially realized event with the help of an adverbial of completion or an aspectual verb, as seen in (28c-f). Cross-linguistically, achievement predicates do not have partitive readings. Thirdly, come does not seem to yield VPs denoting processes, as shown in $(28 \mathrm{~g})$, where the variant with come can only express that John stayed at the station during the interval asserted by the temporal adverbial.

(28) a. \#Ziggy ist 10 Minuten lang zur Schule gekommen.

b. \#Ziggy came to the school for ten minutes.

c. Hans hat es zur Hälfte geschafft zu dem Supermarkt zu laufen [/gehen/ \#kommen].

(Haselbach 2017: 227)

d. Hans managed to drive/go/\#come halfway to the supermarket.

e. Hans konnte zu dem Supermarkt weiter-laufen [/gehen/\#kommen].

(Haselbach 2017: 228)

f. Ziggy could continue walking/going/\#coming to the supermarket.

g. Ziggy (continuously) drove/went/\#came to the station from 14.00 to 14.05 .

Thus while go denotes a set of motion events as seen in (29a), come/kommen denote a set of event boundaries, following Piñón's (1997) definition of achievement verbs. More precisely, they denote transitional boundaries between some motion event $e^{\prime}$ and some state $s$ of being at the location of some contextually supplied entity $a$, which is presupposed to be the location of the speaker in the context $c$, as seen in (29b). The difference between (29a) and (29b) is compatible with Sudo's (2018) proposal that come to $P$ has an indexical presupposition, while go to $P$ does not; rather, go competes with come and triggers an anti-presupposition (Percus 2006).

10 See Fillmore 1966, Oshima 2006, Barlew 2017, Sudo 2018 and Anderson 2020 on the perspective sensitivity and indexical presuppositions of come/go. 
A new case of low modality: Goal PPs

$$
\begin{aligned}
& \text { a. go } \rightsquigarrow \lambda e \cdot \operatorname{motion}(e) \\
& \text { b. come } \rightsquigarrow \lambda e . \exists e^{\prime} \exists s\left[\text { motion }\left(e^{\prime}\right) \wedge e=\operatorname{right-boundary-of}\left(e^{\prime}\right) \wedge\right. \\
& e=\text { left-boundary-of }(s)=\text { location }(a)] \\
& \text { Presupposition: location }(a)=\text { location }(\operatorname{speaker}(c))
\end{aligned}
$$

Since come is an achievement verb (and thus stricto sensu not a motion verb), its subject cannot be agentive (Piñón 1997). Only the event of which come denotes the right boundary may involve an agent. By contrast, the subject of go/gehen can be an agent, as also confirmed by the fact that gehen/go allow -er affixation (der Geher/ the goer), while kommen/go do not (\#der Kommer/\#the comer). Furthermore, come-verbs behave as unaccusative predicates in several respects. For instance, kommen allows for a past participle in prenominal position with an active meaning, which is typical of unaccusatives (Zaenen 1988), while gehen does not when used bare (patterning with manner-of-motion verbs), as (30) shows. Also suggestive is the fact that in several Romance and Germanic languages, several unaccusative verbs par excellence are historically derived from come-verbs (see also Cinque 1972).
a. der gekommene Gast 'the guest who came'
b. der ??gegangene/*gelaufene Gast
Intended: 'the guest who went/ran'

Given that come/kommen, as unaccusative achievement verbs, do not take agent subjects, they force the circumstantial interpretation of $t o / z u$-PPs. This accounts for why the inference that the goal is reached is stronger with come.

\subsection{English vs. German}

Recall that the inference that the goal is reached is globally weaker in German than in English, compare the plots in Figure 3a vs. 3b-3c. We propose that outer aspect is a source of non-culmination in German, but not in English: the German present perfect can not only be interpreted as a perfective, but also as an imperfective; see Bäuerle 1988, Schilder 1997, Löbner 2002, Reyle, Rossdeutscher \& Kamp 2007, Schaden 2011 and Bott \& Hamm 2014. By contrast, in English, the simple past invariably conveys perfectivity with eventive predicates.

\section{References}

Alonso-Ovalle, Luis \& Henrison Hsieh. 2018. Overcoming the unexpected: The Tagalog ability/involuntary action form. In William G. Bennett, Lindsay Hracs \& 
Dennis Ryan Storoshenko (eds.), West Coast Conference on Formal Linguistics (WCCFL) 35, 59-68. Somerville, MA: Cascadilla Proceedings Project.

Anderson, Carolyn. 2020. Shifting the Perspectival Landscape: Methods for Encoding, Identifying, and Selecting Perspectives. Amherst, MA: University of Massachusetts Amherst PhD dissertation.

Arregui, Anna, María Luisa Rivero \& Andrés Salanova. 2017. Introduction. In Modality across Syntactic Categories, 1-8. Oxford: Oxford University Press.

Barlew, Jefferson. 2017. The Semantics and Pragmatics of Perspectival Expressions in English and Bulu: The case of Deictic Motion Verbs. Columbus: The Ohio State University PhD dissertation.

Bäuerle, Rainer. 1988. Ereignisse und Repräsentationen. LILOG-REPORT 43, IBM Deutschland, Stuttgart.

Bott, Oliver. 2010. The Processing of Events. Amsterdam \& Philadelphia: John Benjamins.

Bott, Oliver \& Fritz Hamm. 2014. Cross-linguistic variation in the processing of aspect. In Barbara Hemforth, B. Mertins \& Cathrine Fabricius-Hansen (eds.), Psycholinguistic Approaches to Meaning and Understanding across Languages, 83-109. Berlin: Springer.

Cinque, Guglielme. 1972. Fillmore's semantics of 'come' revisited. Lingua a Stile 7(1). 575-599.

Ermakova, Maria, Julia Lukassek \& Juliane Nau. 2020. Zum Schreien knifflig: zum-Präpositionalphrasen als Adjektivintensivierer. Talk given to the Event semantics Workshop, Universität Tübingen, November 6-7 2020.

Fauconnier, Stefanie. 2012. Constructional Effects of Involuntary and Inanimate Agents: A Cross-linguistic Study. Leuven: Katholieke Universiteit Leuven PhD dissertation.

Fillmore, Charles. 1966. Deictic categories in the semantics of 'come'. Foundations of Language 2. 219-227.

Fischer, Olga. 1997. The grammaticalisation of infinitival to in English compared with German and Dutch. In R. Hickey \& S. Puppel (eds.), Language History and Linguistic Modelling. A Festschrift for Jacek Fisiak on his 60th Birthday, 265-280. Berlin: Mouton de Gruyter.

Gronemeyer, Claire. 2001. Modal readings of light verbs with to-infinitivals. Working Papers in Scandinavian Syntax 48. 55-65.

Haselbach, Boris. 2013. Expressing to in German: in/ nach/ zu/*bei. Talk presented at the Workshop Variation in $P$, Università Ca' Foscari, Venice, 10-11 October 2013. www.sfb732.uni-stuttgart.de/documents/files/varp2013-slides.pdf.

Haselbach, Boris. 2017. Ps at the interfaces: On the Syntax, Semantics, and Morphology of Spatial Prepositions in German. Stuttgart: IMS, University of Stuttgart $\mathrm{PhD}$ dissertation. 
A new case of low modality: Goal PPs

Haspelmath, Martin. 1989. From purposive to infinitive - A universal path of grammaticalization. Folia Linguistica Historica X/1-2. 287-310. doi:10.1515/flih.1989.10.1-2.287.

Heyde-Zybatow, Tatjana. 2008. What kind of events do achievements describe? In Anita Steube (ed.), The Discourse Potential of Underspecified Structures, 109-144. Berlin: De Gruyter.

Hirschberg, Julie. 1991. A Theory of Scalar Implicature. New York: Garland.

Holl, Daniel. 2010. Modale Infinitive und dispositionelle Modalität im Deutschen. Berlin: Akademieverlag.

Landman, Fred. 1992. The progressive. Natural Language Semantics 1. 1-32. doi:10.1007/BF02342615.

Löbner, Sebastian. 2002. Is the German Perfekt a perfect perfect? In Graham Katz, Sabine Reinhard \& Philip Reuter (eds.), Sinn und Bedeutung, vol. 6, 255-274.

Los, Bettelou. 2005. The rise of the to-infinitive. Oxford: Oxford University Press.

Lukassek, Julia, Anna Prysłopska, Robin Hörnig \& Claudia Maienborn. 2017. The semantic processing of motion verbs: coercion or underspecification? Journal of Psycholinguistic Research 46(4). 805-825.

Martin, Fabienne. 2015. Explaining the link between agentivity and non-culminating causation. In Sarah D’Antonio, Mary Moroney \& Carol Rose Little (eds.), Semantics and Linguistic Theory (SALT) 25, 246-266. doi:10.3765/salt.v25i0.3060.

Martin, Fabienne \& Florian Schäfer. 2012. The modality of 'offer' and other defeasible causative verbs. In Nathan Arnett \& Ryan Bennett (eds.), West Coast Conference on Formal Linguistics (WCCFL) 30, 248-258. Somerville, MA: Cascadilla Press.

Mittwoch, Anita. 1988. Aspects of English aspect: On the interaction of perfect, progressive and durational phrases. Linguistics \& Philosophy 11/2. 203-254. doi:10.1007/BF00632461.

Nakazawa, Tsuneko. 2006. Motion event and deictic motion verbs as path-conflating verbs. In HPSG06 Conference, 284-304. Stanford, CA: CSLI Publications.

Naumann, Ralf \& Christopher Piñón. 1997. Decomposing the progressive. In Paul Dekker, Martin Stokhof \& Yde Venema (eds.), Amsterdam Colloquium 11, 241-246. Amsterdam: ITLI, University of Amsterdam.

Oshima, David. 2006. Motion deixis, indexicality, and presupposition. In Masayuki Gibson \& Jonathan Howell (eds.), Semantics and Linguistic Theory (SALT) 16, 172-189. Ithaca, NY: CLC, Cornell University. doi:10.3765/salt.v16i0.2942.

Percus, Orin. 2006. Antipresuppositions. Technical report, Japan Society for the Promotion of Science. Report of the Grant-in-Aid for Scientific Research (B), Project No. 15320052.

Piñón, Christopher. 1993. Paths and their names. In Katharine Beals, Gina Cooke, David Kathman, Sotaro Kita, Karl-Erik McCullough \& David Testen (eds.), 29th 
Regional Meeting of the Chicago Linguistic Society, vol. 2, 287-303. Chicago: CLS.

Piñón, Christopher. 1997. Achievements in an event semantics. In Aaron Lawson (ed.), Semantics and Linguistic Theory (SALT) 7, 273-296. Ithaca, NY: Cornell University. doi:10.3765/salt.v7i0.2781.

Reyle, Uwe, Antje Rossdeutscher \& Hans Kamp. 2007. Ups and downs in the theory of temporal reference. Linguistics \& Philosophy 30. 565-635. doi:10.1007/s10988-008-9027-0.

Schaden, Gerhard. 2011. Introducing the present perfective puzzle. In Walter de Mulder, Jesse Mortelmans \& Tanja Mortelmans (eds.), From Now to Eternity, 105-122. Amsterdam: Rodopi.

Schilder, Frank. 1997. Temporal Relations in English and German Narrative Discourse. Edinburgh: University of Edinburgh $\mathrm{PhD}$ dissertation.

Smith, Carlota. 1997. The Parameter of Aspect. Dordrecht: Kluwer.

Sudo, Yasutada. 2018. Come vs. go and perspectival shift. Hand-out for a talk at Rutgers University, 14 February 2018.

Varasdi, Károly. 2014. Making progressives: Necessary conditions are sufficient. Journal of Semantics 31. 179-207. doi:10.1093/jos/fft004.

Zaenen, Annie. 1988. Unaccusative Verbs in Dutch and the Syntax-semantics Interface. CSLI Reports 88-123. Stanford, CA: CSLI, Stanford University.

Zucchi, Sandro. 1998. Aspect shift. In Susan Rothstein (ed.), Events and Grammar, 349-370. Dordrecht: Kluwer.

Zwarts, Joost. 2005. Prepositional aspect and the algebra of paths. Linguistics \& Philosophy 28(6). 739-779. doi:10.1007/s10988-005-2466-y.

Fabienne Martin

Department of English and American Studies

Humboldt-Universität zu Berlin

Unter den Linden 6

10117 Berlin

fabienne.martin@hu-berlin.de

Florian Schäfer

Department of English and American Studies

Humboldt-Universität zu Berlin

Unter den Linden 6

10117 Berlin

florian.schaefer2@hu-berlin.de
Margaret Grant

Simon Fraser University

RCB 8115

8888 University Drive

Burnaby, BC V5A 1S6

margaret_grant@sfu.ca

Christopher Piñón

STL UMR 8163

Université de Lille

Campus Pont-de-bois

Rue du Barreau, BP 60149

Villeneuve d'Ascq Cedex 59653

cjpinon@implicature.xyz 